\title{
Cervical ripening with self administered iso sorbide mononitrate vaginally, in uncomplicated singleton pregnancies at 39 weeks gestation: a double blind randomised controlled trial
}

\author{
K Attanayake', M Goonewardene ${ }^{1}$ \\ (Index words: cervical ripening, nitric oxide donor, vaginal iso sorbide mononitrate)
}

\begin{abstract}
Introduction Vaginal iso sorbide mononitrate (ISMN) is effective in pre induction cervical ripening in post dated pregnancies.

Objectives To determine the effectiveness and acceptability of ISMN self-administered vaginally at home, in causing cervical ripening in uncomplicated singleton pregnancies at 39 weeks gestation.
\end{abstract}

Methods Consecutive women with uncomplicated singleton pregnancies, presenting between 01 October 2013 and 31 March 2014, with a modified Bishop score (MBS) of $<5$ at a gestational age (GA) of 273 days to the University Obstetric Unit of Teaching Hospital Mahamodera Galle, were allocated by stratified (primip/multip) block randomisation to self-administer vaginally at home every other day, five doses of $60 \mathrm{mg}$ of sustained release form of ISMN (ISMN-SR); $(n=72$, cases), or pyridoxine 10 mgs ( $n=72$, controls), from GA 273 to 282 days.

Results The mean MBS and the mean change of MBS at 282 days, and the proportions with spontaneous onset of labour (SOL) by GA 282 days, were not significantly different between the two groups. A vast majority were satisfied with outpatient therapy $(80 \%$ cases vs.76\% controls), were happy to use it in a subsequent preg-nancy ( $89 \%$ cases vs. $86 \%$ controls) and would recom-mend it to a friend ( $93 \%$ cases vs. $90 \%$ controls).

Conclusions Home adminstrated vaginal ISMN therapy from GA 39 weeks was not effective in causing significant cervical ripening or promoting SOL, but it was acceptable to women.

Ceylon Medical Journal 2016; 61: 142-148

http://doi.org/10.4038/cmj.v61i4.8378

\section{Introduction}

The median gestational age (GA) at spontaneous onset of labour (SOL) in uncomplicated singleton pregnancies in South Asian women is approximately 39 weeks and therefore is less than that in Caucasians [1-7]. Even in low risk women, maternal complications of pregnancy increase after 40 weeks of gestation [8-11]. Furthermore perinatal mortality is higher at all gestational ages, in South Asian women compared to Caucasians [8].

Vaginally administered nitric oxide (NO) donors e.g. iso sorbide mono nitrate (ISMN), are safe and effective for pre induction cervical ripening and has been used in different outpatient settings with minimal maternal and fetal adverse effects [12 - 20]. This therapy did not increase anxiety and women found it acceptable [21,22]. It is also cost effective [23].

It is necessary to identify the optimal dose and frequency as well as safety, and cost effectiveness of outpatient pre induction cervical ripening and induction of labour ( IOL) in order to reduce the time women spend in hospital $[24,25]$. A study carried out in the Academic Obstetric Unit of the Teaching Hospital Mahamodera Galle (THMG) found that the median GA among the women with uncomplicated singleton pregnancies who established SOL and delivered vaginally, without any obstetric intervention, was approximately 39 weeks +2 days. [Attanayake and Goonewardene unpublished data]. As the median GA at SOL is approximately 39 weeks in Sri Lankans, it may be prudent if women in Sri Lanka are delivered around 40 weeks of gestation. It would be preferable if the onset of SOL could be facilitated with a simple intervention like self-administration of vaginal ISMN as an outpatient procedure prior to 40 weeks of gestation, without resorting to formal IOL.

${ }^{1}$ University Obstetrics and Gynaecology Unit, Teaching Hospital Mahamodara, Galle, Sri Lanka.

Correspondence: MG, e-mail: <malikg@eureka.lk>. Received 6 May 2016 and revised version accepted 25 August 2016.

This is an open-access article distributed under the terms of the Creative Commons Attribution License, which permits unrestricted use, distribution, and reproduction in any medium, provided the original author and source are credited. 
The sustained form of ISMN (ISMN-SR) has been used as an in-ward procedure vaginally for pre-induction cervical ripening of post dated pregnancies in the Academic Obstetric Unit of the THMG since 2003, and varying doses and frequencies of administration have been studied [13-15]. The current study was designed to determine the effectiveness and acceptability of self-administered vaginal ISMN-SR 60 mgs every other day for five doses, self-administered at home in causing cervical ripening in women with singleton, uncomplicated pregnancies at 39 weeks of gestation having a modified Bishop Score (MBS) $<5$ out of 10 [26].

\section{Method}

A previous study carried out in the unit indicated that approximately $46 \%$ of women with uncomplicated singleton pregnancies would establish SOL and deliver normally between 39 weeks and 40 weeks +2 days of gestation [Attanayake and Goonewardene unpublished data]. Therefore, to detect a $25 \%$ increase in this percentage in the ISMN group with a power of $80 \%$ and an alpha error of 5\% the minimum sample size was calculated to be 72 participants for a two arm randomised control trial [27]. The addition of $15 \%$ to allow for post randomization exclusions due to non compliance resulted in a targeted sample of 166 participants.

\section{Inclusion and exclusion criteria}

Between 01 October 2013 and 31 March 2014, women scheduled for admission to the University Obstetric Unit of the THMG for delivery were interviewed and examined at the antenatal clinic at 39 weeks. The inclusion criteria included all of the following: uncomplicated pregnancy at 39 weeks GA with a singleton fetus having a cephalic presentation and a MBS $<5$ out of 10 , and consenting to self-administer the vaginal tablets every other day for five days. Any pregnancy with complications e.g. hyper-tension or hyperglycaemia in pregnancy, multiple pregnancies, planned caesarean delivery, fetal growth restriction and history of hypersensitivity or idiosyncratic reaction to nitrates were excluded from the study. Informed written consent was obtained from all the participants of the study.

\section{Randomisation}

Using computer generated random numbers participants were allocated to study and control groups by stratified (Primips / Multips) block randomisation. Two sets of sequentially numbered opaque envelopes (one for Primips and one for Multips) were packed with five tablets of either ISMN-SR $60 \mathrm{mgs}$ (Angifree - SR, Microlabs, Bangalore, India) or five tablets of Pyridoxine 10mgs (Health Aid Vitamins, Harrow, Middlesex, United Kingdom) according to the random allocation sequence in blocks of four, by the second author. Each block had ISMN-SR $60 \mathrm{mgs}$ or Pyridoxine $10 \mathrm{~m}$ in the ratio of 1:1.

\section{Intervention}

The participants were instructed to self-administer the tablets vaginally at home at GAs of 39 weeks, 39 weeks +2 days, 39 weeks +4 days, 39 weeks +6 days and 40 weeks +1 day, unless SOL was established and needed admission to hospital. If SOL was not established by 40 weeks +2 days, all participants were admitted to hospital, the MBS was re-assessed and artificial separation of membranes was carried out if feasible, and if not feasible, a cervical massage were carried out. If SOL was not established by 41 weeks the routine management guideline for cervical ripening and IOL of the unit was followed. This included artificial separation of membranes, administrating prostaglandin ( $\mathrm{PGE}_{2}-3 \mathrm{mg}$ tablets) vaginally or by intra cervical Foley catheter, followed by amniotomy and intravenous oxytocin infusion. On admission to hospital either with SOL or GA at 40 weeks +2 days, compliance was assessed by checking the cards which the participants had been requested to maintain, indicating when they self administered the study medication.

\section{Outcome measures}

Percentage of SOL between GA of 39 weeks and 40 weeks +2 days and between GA of 40 weeks +2 days and 40 weeks +5 days, and their modes of delivery were documented. The MBS at GAs of 40 weeks +2 days and 40 weeks +5 days, and the change in the MBS between these GAs were documented. The requirement for vaginal $\mathrm{PGE}_{2}$ or intra cervical Foley catheter between GA of 40 weeks +5 and 40 weeks +6 days and the MBS at 41 weeks gestation was documented. Requirement of IOL with oxytocin and amniotomy and the induction delivery intervals at 41 weeks gestation, the modes of delivery and the birth weight of the neonates and the neonatal outcome were documented. Side effects of the interventions and the satisfaction and acceptability of administration at home were assessed with a structured interviewer administered questionnaire before the participants left hospital.

\section{Statistical analysis}

Continuous variables are presented as means and $95 \%$ confidence intervals $(95 \% \mathrm{CI})$ if they are normally distributed and medians and inter-quartile ranges (IQR) if they are not, and compared with the t test and the Mann-Whitney U test respectively. Proportions were calculated for categorical data and compared using the Chi Square test. All primary analyses were performed according to the intention to treat principle. All data were analysed using IBM Statistical Programme for Social Sciences (SPSS) version 20. Approval was obtained from the Ethical Review Committee, Faculty of Medicine, University of Ruhuna and the Director of the THMG. The study was registered in the Sri Lanka Clinical Trials Registry. 
Figure 1. Study Flow Diagram

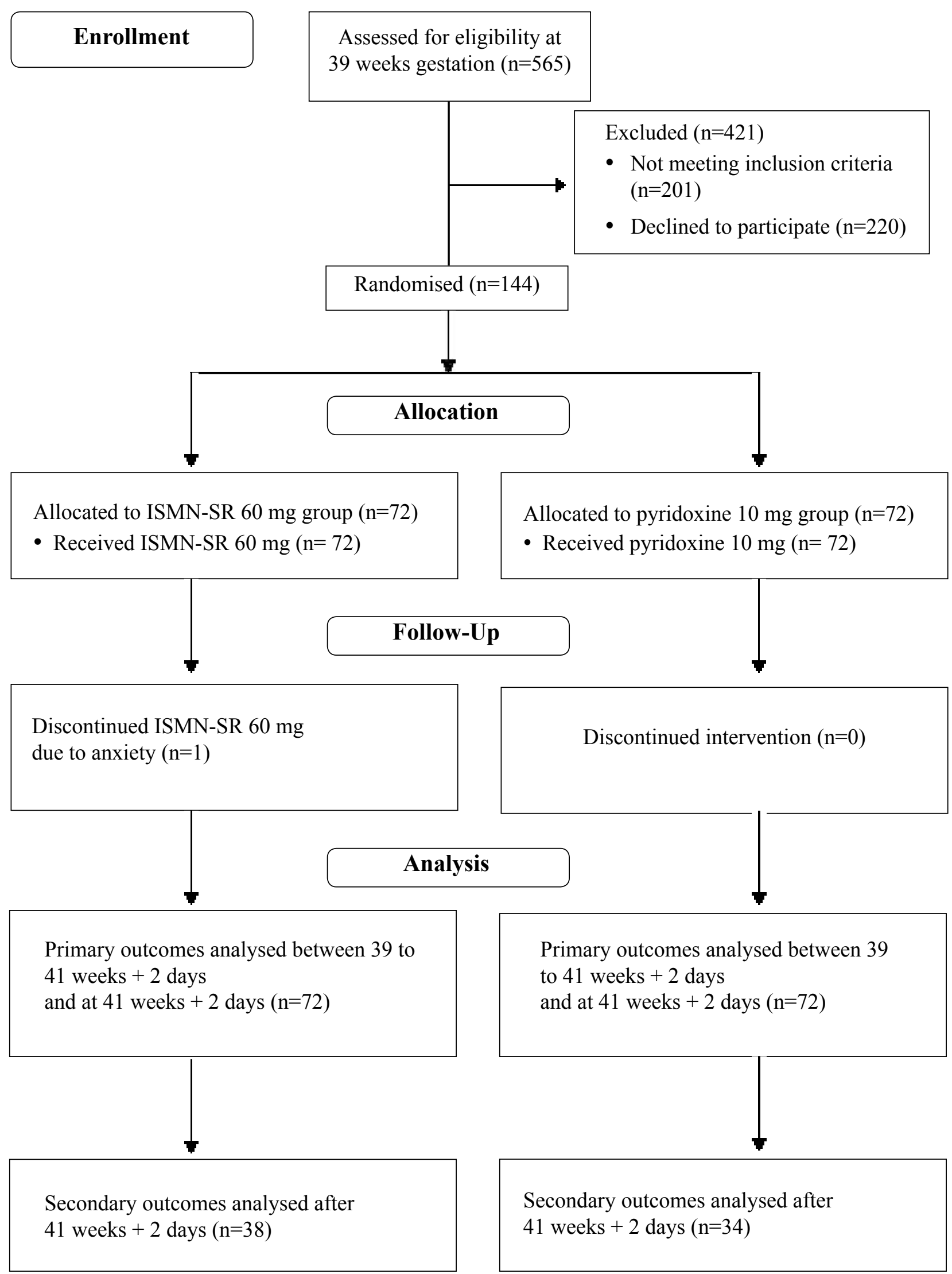




\section{Results}

The targeted number of 83 primigravida were recruited but only 61 multigravida could be recruited as many multigravidae declined consent to participate in the study. This resulted in 144 women being randomised, ( $\mathrm{n}=72$ allocated to each group), which was the minimum sample size required. One woman withdrew from the study after being randomised. She was included in the intention to treat analysis at 41 weeks +2 days, but excluded from the secondary analyses thereafter (Figure 1). There were no significant differences between the basic characteristics in the two groups confirming that the stratified (primip, multip) block randomisation was optimum (Table 1).
There were no significant differences between the two groups in the proportions establishing SOL (47\% in the ISMN-SR group vs $53 \%$ in the pyridoxine group) or having a normal delivery ( $42 \%$ in the ISMN-SR group vs $49 \%$ in the pyridoxine group) between 39 weeks and 40 weeks +2 days (Table 2). There was no significant difference in compliance between the two groups. The majority of participants had taken at least three doses of treatment by 40 weeks +2 days $(78 \%$ in the ISMN-SR group vs $73 \%$ in the pyridoxine group). However only $42 \%$ had complied with self administration of all five doses of ISMN-SR. There were no significant differences in the mean MBS or the mean change in MBS between the two groups, both in primips and multips at 40 weeks + 2 days (Table 3 ).

Table 1. Characteristics of the participants $(n=144)$

\begin{tabular}{|c|c|c|c|}
\hline & $\begin{array}{c}S M N-S R \\
60 m g s \\
(n=72)\end{array}$ & $\begin{array}{c}\text { Pyridoxine } \\
\text { 10mgs } \\
(n=72)\end{array}$ & $p$ value* \\
\hline Primigravida & $42(58 \%)$ & $41(57 \%)$ & $0.866^{*}$ \\
\hline Mean age of primips-Years $(95 \% \mathrm{CI})$ & $25.1(16.1$ to 34.1$)$ & $25.2(14.6$ to 35.8$)$ & $0.385 * *$ \\
\hline \multicolumn{4}{|l|}{ Education Level } \\
\hline 5 th to 10 th grade & 0 & $1(2.5 \%)$ & $0.315^{*}$ \\
\hline GCE Ordinary Level & $31(74 \%)$ & $25(61 \%)$ & $0.305^{*}$ \\
\hline GCE Advanced Level or above & $11(26 \%)$ & $15(37 \%)$ & $0.386^{*}$ \\
\hline Baseline mean MBS(SD) & $2.0(1.21)$ & $2.2(1.26)$ & $0.295^{* *}$ \\
\hline Multigravidae & $30(42 \%)$ & $31(43 \%)$ & $0.866^{*}$ \\
\hline Mean age of multips-Years $(95 \% \mathrm{CI})$ & $30.2(22.6$ to 37.8$)$ & $29.9(21.2$ to 38.6$)$ & $0.310^{* *}$ \\
\hline \multicolumn{4}{|l|}{ Education Level } \\
\hline$<5$ th grade & 0 & $3(10 \%)$ & $0.080^{*}$ \\
\hline 5 th to 10 th grade & $3(10 \%)$ & $2(6 \%)$ & $0.648^{*}$ \\
\hline GCE Ordinary level & $21(70 \%)$ & $17(55 \%)$ & $0.449 *$ \\
\hline GCE Advanced Level or above & $6(20 \%)$ & $9(29 \%)$ & $0.413 *$ \\
\hline Baseline mean MBS(SD) & $2.8(1.33)$ & $2.5(1.17)$ & $0.354 * *$ \\
\hline
\end{tabular}

* by comparison of proportions using Chi square ** by comparison of means using t-test

Table 2. Outcome between 39 weeks and 40 weeks +2 days $(n=144)$

\begin{tabular}{|c|c|c|c|}
\hline & $\begin{array}{c}I S M N-S R \\
60 m g s \\
(n=72)\end{array}$ & $\begin{array}{c}\text { Pyridoxine } \\
\text { 10mgs } \\
\text { or above }\end{array}$ & $p$ value* \\
\hline Spontaneous onset of labour & $34 * * *$ & 38 & $0.504 *$ \\
\hline Normal delivery & 30 & 35 & $0.402 *$ \\
\hline Mean birth weight (SD) & $3055 \mathrm{~g}(316)$ & $3052(312)$ & $0.233 * *$ \\
\hline $95 \% \mathrm{CI}$ & $2420 \mathrm{~g}-3670 \mathrm{~g}$ & $2521 g-3751 g$ & \\
\hline SCBU admissions & 1 & 1 & - \\
\hline Not delivered & 38 & 34 & 0.504 \\
\hline
\end{tabular}

* by comparison of proportions using Chi square $\quad * *$ by comparison of means with t-test $\quad * * *$ one drop out after randomisation $\mathrm{SCBU}=$ Special Care baby unit; $\mathrm{SD}=$ standard deviation; $95 \% \mathrm{CI}=95 \%$ confidence interval 
Table 3. Outcome in the women undelivered at 40 weeks +2 days $(n=72)$

\begin{tabular}{|c|c|c|c|}
\hline & $\begin{array}{c}I S M N-S R \\
60 m g s \\
(n=38) * *\end{array}$ & $\begin{array}{c}\text { Pyridoxine } \\
\text { 10mgs } \\
(n=34)\end{array}$ & $p$ value* \\
\hline Overall mean MBS (SD) & $3.6(1.33)$ & $3.3(1.39)$ & 0.723 \\
\hline Overall MBS change (SD) & 5 & $3(1.8)$ & 0.669 \\
\hline
\end{tabular}

* by comparison of means using t-test

** one drop out after randomization

MBS $=$ Modified Bishops Score; NS = Not significant, $95 \%$ CI = 95\% Confidence Interval

Table 4. Side effects of self medication

\begin{tabular}{lccc}
\hline & $\begin{array}{c}\text { ISMN-SR } \\
60 \mathrm{mgs}\end{array}$ & $\begin{array}{c}\text { Pyridoxine } \\
10 \mathrm{mgs}\end{array}$ & $p$ \\
value* & $(n=72)$ & $(n=72)$ & \\
Headache & $32(44 \%)$ & $11(15 \%)$ & $<0.001$ \\
Vomiting & $5(7 \%)$ & $1(1 \%)$ & 0.095 \\
Dizziness & $1(1 \%)$ & 0 & 0.315 \\
Nausea & $3(5 \%)$ & $2(3 \%)$ & 0.648 \\
No side effect & $31(43 \%)$ & $58(80 \%)$ & $<0.001$ \\
\hline
\end{tabular}

* by comparison of proportions using Chi square

**one drop out after randomization

There were no significant differences in maternal satisfaction and acceptability between the two groups and $>75 \%$ of women in both groups considered selfadministered therapy at home as a better intervention than in-ward therapy. More than $85 \%$ were happy to use home administration in a subsequent pregnancy and would also recommend it to a friend. Side effects were commoner in the ISMN-SR group compared to the pyridoxine group ( $57 \%$ vs $20 \%, p<001)$. The main side effect observed in the ISMN-SR group was headache, which was significantly higher $(p<0.05)$ in the ISMN-SR group compared to the pyridoxine group (Table 4).

There were no significant differences in the outcomes between 40 weeks +2 days and 40 weeks +5 days in both primips and multips. Approximately $89 \%$ in both groups established SOL and the majority $(>65 \%)$ of them had a normal delivery. There were also no significant differences in the proportions of women requiring additional cervical ripening modalities at 40 weeks + 5 days, in both primips ( 2 vs 5 ) and multips (3 vs 1) in the ISMN-SR and pyridoxine groups respectively. There were no significant differences in the mean MBS, IOL and augmentation of labour rates, mean induction to delivery rates, oxytocin requirements, mode of delivery or maternal and neonatal outcomes between the two groups, both in primips and multips at 41 weeks gestation. There was a non significant increase in the number of neonates admitted to the NICU in the pyridoxine group compared to the ISMN group (4 vs 0 ).

\section{Discussion}

The NO donor ISMN did not improve the cervical favourability for IOL or significantly increase the establishment of SOL after self administration at home at 39 weeks gestation. However the fact that maternal satis-faction was very high with three out of four women preferring to use home self administration in a subsequent pregnancy, and also being happy to recommend such therapy to a friend, are important findings. Furthermore, no clinically significant increase in maternal or neonatal morbidity was observed with the vaginal ISMN therapy. Although pre IOL cervical ripening effects of vaginal ISMN has been well demonstrated in postdated pregnancies of 41 weeks or more, attempts at ripening the cervix at 39 weeks does not appear to be justified as more than $50 \%$ of the controls established SOL prior to 40 weeks +2 days. The majority in the ISMN group developed headache, the commonest side effect of ISMN therapy, indicating that it was absorbed by the vaginal epithelium. Only $42 \%$ had complied with self administration of all five doses. Therefore, the non effectiveness of the self administration of ISMN-SR $60 \mathrm{mg}$ could have been be due to suboptimal dosage. Whether the results could have been different if the treatment was administered by a health care person, needs to be considered.

The use of vaginally administered NO donors cannot be considered as a method of IOL because NO donors only cause morphological changes in the uterine cervix, and do not initiate uterine contractions. Therefore outcome measures such as time to vaginal delivery and vaginal delivery not achieved in 24 hours, used for assessment of therapies for IOL, are not appropriate for studies on vaginally administered NO donors. The main advantage

Ceylon Medical Journal 
of vaginally administered NO donors for pre IOL cervical ripening is the fact that this method does not require fetal monitoring and therefore it can be instituted at home, without admission to hospital. The main advantage shown by outpatient self administered vaginal ISMN has been a reduction in hospital admission to delivery intervals [18-20]. However in our unit women often self admit themselves to hospital within a day or two of completion of 40 weeks gestation if they have not established SOL. This is primarily due to maternal anxiety and some times due to transport difficulties. These women usually await SOL in hospital, with low key interventions such as sweeping of the membranes and vaginal ISMN. They undergo IOL only at 41 weeks gestation with amniotomy and oxytocin infusion. Pre IOL cervical ripening with $\mathrm{PGE}_{2}$ and or intracervical insertion of Foley catheter is carried out if needed. As a result of this process, hospital admission to delivery intervals vary considerably in the unit, and therefore this outcome is not satisfactory.

In the current study, home self administration of ISMN-SR was not associated with any significant reduction in the need for additional cervical ripening prior to IOL at 41 weeks gestation. This is similar to the findings of the IMOP study in which three doses of $40 \mathrm{mgs}$ ISMN were administered at 48, 32 and 16 hours before admission [18]. These findings however are contrary to the findings of Habib et al who found a reduced need for vaginal $\mathrm{PGE}_{2}$ after outpatient ISMN therapy [20]. Even though the numbers were small, the IOL and augmentation rates at 41 weeks were not significantly different between the groups. This aspect has not been assessed in other studies. There was no significant differences in mode of delivery, duration of labour and oxytocin requirements during labour in the ISMN treated group, and this is comparable to the findings of previous studies [18-20]. The mean induction delivery intervals in the current study were markedly shorter than in the IMOP study and this may be due to the majority of women in the IMOP study having epidural analgesia during labour and the relatively high doses of oxytocin used for IOL in the academic obstetric unit of THMG. Vaginal ISMN treatment was well tolerated by the women. Although many reported a mild headache which responded to paracetamol, none withdrew from the study due to side effects. The non significant increase in the number of neonates admitted to the NICU in the pyridoxine group compared to the ISMN group was probably a random occurrence associated with the delivery. In the IMOP study there were no significant differences in NICU admissions between the treatment and placebo groups, and although NICU stay was longer in the ISMN group, this was not attributable to ISMN therapy [18].

Recruitment of women for the self administration of vaginal ISMN at home was difficult as it was not a routine practice, and in spite of an indepth explanation of the minimal maternal and fetal side effects, women were worried about taking drugs prior to their 'Expected Date of Delivery'. The relatively long interval between the intervention and the assessment of cervical favourability as a primary outcome resulted in approximately $50 \%$ establishing SOL, the other primary outcome. The adoption of a higher dosing schedule over a shorter time duration may enable the cervical changes to be better assessed after vaginal ISMN. The use of a graded self administered questionnaire after the delivery, to assess maternal satisfaction and side effects of self administration could have resulted in biased responses and the use of anxiety scores and pain scores may have given more objective responses regarding the acceptability of the interventions. Further research should focus on studying the effects and the value of self administering at home vaginal ISMN between 40 weeks and 41 weeks gestation, in facilitating SOL and or making the cervix favourable for IOL. The optimum formulation, dose and frequency of administration of vaginal ISMN as well as the optimum GA at administration to obtain the best results, have not been established as yet. There is a need to find an effective self administered agent to achieve outpatient cervical ripening. Such an agent would be very popular with women awaiting SOL or IOL.

In conclusion, home self administration of the NO donor ISMN-SR $60 \mathrm{mg}$ vaginally, every other day for five days from 39 weeks gestation, was not effective in increasing the proportion of women establishing SOL or becoming favourable for IOL at 40 weeks +2 days.

\section{Conflicts of interest}

There are no conflicts of interest.

\section{References}

1. Patel RR, Steer P, Doyle P, Little MP, Elliot P. Does gestation vary by ethnic group? A London-based study of over 122000 pregnancies with spontaneous onset of labour. Int J Epidemiol 2004; 33: 107-13.

2. Omigbodun AO, Adewuyi A. Duration of human singleton pregnancies in Ibadan, Nigeria. J Nati Med Assoc 1997; 89: 617-21.

3. Papiernik E, Alexander GR, Paneth N. Racial differences in pregnancy duration and its implications for perinatal care. Med Hypotheses 1990; 33: 181-6.

4. Migone A, Emanuel I, Mueller B, Daling J, Little RE. Gestational duration and birthweight in White, Black and mixed-race babies. Paediatr Perinat Epidemiol 1991; 5: 378-91.

5. Mathai M, Thomas S, Peedicayil A, Regi A, Jasper P, Joseph R. Growth pattern of the Indian fetus. Int J Gynaecol Obstet 1995; 48: 21-4. 
6. Shiono PH, Klebanoff MA. Ethnic differences in preterm and very preterm delivery. Am J Public Health 1986; 76: 1317-21.

7. Aveyard P, Cheng KK, Manaseki S, Gardosi J. The risk of preterm delivery in women from different ethnic groups. BJOG 2002; 109: 894-9.

8. Balchin I, Steer PJ, Whittaker JC, Patel V, Lamont RF. Racial variation in the association between gestational age and perinatal mortality: prospective study. British Medical Journal 2007; 334: 833. doi: 10.1136/bmj.39132.482025.80

9. Caughey AB, Aaron B, Thomas J. Complications of Term Pregnancies Beyond 37 Weeks of Gestation.Obstet Gynecol 2004; 103: 57-62.

10. Balchin I, Whittaker JC, Lamont RF, Steer PJ. Maternal and Fetal Characteristics Associated With Meconium-Stained Amniotic Fluid. Obstet Gynecol 2011; 117: 828-35.

11. Hogue CJ, Silver RM. Racial and ethnic disparities in United States: stillbirth rates: trends, risk factors, and research needs. Semin Perinatol 2011; 35: 221-33.

12. Erling E, Bullarbo M, Björn A, Norström A. Vaginal administration of the nitric oxide donor iso sorbide mononitrate for cervical ripening at term: a randomized controlled study. Am J Obstet Gynecol 2003; 189: 1692-7.

13. Rameez MFM, Goonewardene IMR. Nitric oxide donor isosorbide mononitrate for pre-induction cervical ripening at 41 weeks' gestation: A randomized controlled trial. $J$ Obstet Gynaecol Res 2007; 33: 452-6.

14. Vidanagamage RS, Goonewardene IMR. The efficacy of two different doses of vaginal Iso sorbide mononitrate in pre-induction cervical ripening: a double blind randomized controlled trial. Ceylon Med J 2011; 56: 91-100.

15. Ziard MH, Goonewardene IMR. Efficacy of two different treatment regimens of vaginal nitric oxide donor (iso sorbide mononitrate) used for pre-induction cervical ripening. SL Journal of Obstetrics and Gynaecology 2012; 34: 81 .

16. Thomson AJ, Lunan CB, Cameron AD, Cameron IT, Greer IA, Norman JE. Nitric oxide donors induce ripening of the human uterine cervix: a randomised controlled trial. BJOG 1997; 104: 1054-7.

17. Nicoll AE, Mackenzie F, Greer IA, Norman JE. Vaginal application of the nitric oxide donor iso sorbide mononitrate for preinduction cervical ripening: a randomized controlled trial to determine effects on maternal and fetal heamodynamics. Am J Obstet Gynecol 2001; 184: 958-64.

18. Bollapragada SS, Mackenzie F, Norrie JD, Eddama O, Petrou S, Reid M. Randomised placebo-controlled trial of outpatient (at home) cervical ripening with isosorbide mononitrate (ISMN) prior to induction of labour: clinical trial with analyses of efficacy and acceptability. The IMOP study. BJOG 2009; 116: 1185-95.

19. Bullarbo M, Orrskog ME, Andersch B. Outpatient vaginal administration of the nitric oxide donor iso sorbide mononitrate for cervical ripening and labor induction post term: a randomized controlled study. Am J Obstet Gynecol 2007; 196: 50.

20. Habib SM, Emam SS, Saber AS. Outpatient cervical ripening with nitric oxide donor iso sorbide mononitrate prior to induction of labor. Int J Gynaecol Obstet 2008; 101: 57-61.

21. Agarwal K, Batra A, Batra A, Dabral A, Aggarwal A. Evaluation of iso sorbide mononitrate for cervical ripening prior to induction of labor for postdated pregnancy in an outpatient setting. Int J Gynecol Obstet 2012; 118: 205-9.

22. Osman I, MacKenzie F, Norrie J, Murray HM, Greer IA, Norman JE. The "PRIM" study: a randomized comparison of prostaglandin E2 gel with the nitric oxide donor iso sorbide mononitrate for cervical ripening before the induction of labor at term. Am J Obstet Gynecol 2006; 194: 1012-21.

23. Eddama O, Petrou S, Schroeder L, et al. The costeffectiveness of outpatient (at home) cervical ripening with iso sorbide mononitrate prior to induction of labour. $B J O G$ 2009; 116: 1196-203.

24. Kelly AJ, Munson C, Minden L. Nitric oxide donors for cervical ripening and induction of labour. Cochrane Database of Syst Rev 2011, issue 6. Art. No.: CD006901. DOI:10. 1002/14651858.CD006901.pub2. (accessed 17 July 2013).

25. Goonewardene M, Rameez MFM, Kaluarachchi A, Perera H. WHO recommendations for induction of labour: RHL commentary (last revised: 1 November 2011). The WHO Reproductive Health Library; Geneva: World Health Organization.

26. Bishop EH. Pelvic Scoring for Elective Induction. Obstetrics and Gynecology 1964; 24: 266-8.

27. Lwanga SK, Cho-Yook Tye, Ayeni O. Teaching Health Statistics - Lessons and Seminar Outlines Second Edition, WHO 1999: 77-78. Geneva: World Health Organization. 